Ben van der Hoven Yorick J. de Groot Wilhelmina J. Thijsse Erwin J. O. Kompanje

\title{
What to do when a competent ICU patient does not want to live anymore but is dependent on life-sustaining treatment? Experience from The Netherlands
}

Received: 4 November 2009

Accepted: 21 June 2010

Published online: 6 August 2010

(C) The Author(s) 2010. This article is published with open access at Springerlink.com

This article is discussed in an editorial available at:

doi:10.1007/s00134-010-1958-6.

B. van der Hoven (®) ·

Y. J. de Groot - W. J. Thijsse .

E. J. O. Kompanje

Department of Intensive Care, Erasmus MC University Medical Center, PO Box 2040,

3000 CA Rotterdam, The Netherlands

e-mail: b.vanderhoven.1@erasmusmc.nl

Tel.: +31-10-7040704

Fax: +31-10-7036978
Abstract If patients on the intensive care unit (ICU) are awake and life-sustaining treatment is suspended because of the patients' request, because of recovering from the disease, or because independence from organ function supportive or replacement therapy outside the ICU can no longer be achieved, these patients can suffer before they inevitably die. In The Netherlands, two scenarios are possible for these patients: (1) deep palliative (terminal) sedation through ongoing administration of barbiturates or benzodiazepines before withdrawal of treatment, or (2) deliberate termination of life (euthanasia) before termination of treatment. In this article we describe two awake patients who asked for withdrawal of life-sustaining measures, but who were dependent on mechanical ventilation. We discuss the doctrine of double effect in relation to palliative sedation on the ICU. Administration of sedatives and analgesics before withdrawal of treatment is seen as normal palliative care. We conclude that the doctrine of the double effect is not applicable in this situation, and mentioning it criminalised the practice unnecessarily and wrongfully.

Keywords End of life - ICU · Palliative care - Palliative sedation . Treatment withdrawal

\section{Introduction}

Some conscious patients on the ICU request withdrawal of life-sustaining treatment in order to die. In The Netherlands two scenarios can be offered: (1) deep palliative sedation through administration of barbiturates or benzodiazepines before withdrawal of treatment, or (2) we can offer deliberate termination of life (euthanasia) before termination of treatment. The aim of palliative sedation is to prevent suffering by lowering consciousness as a means to achieve this. In this context, it is important to understand that withdrawal of treatment, consequently allowing the patient to die, after intentional lowering of consciousness is not equivalent with euthanasia or deliberate termination of life $[1,2]$. Euthanasia is the intentional termination of life of an adult patient on his or her request. This presupposes voluntariness and a deliberate act, and excludes every form of intentional non-voluntary termination of life. Usually the patient is sedated to unconsciousness and then given a barbiturate and muscle-paralysing agent. In the Termination of Life on Request and Assisted Suicide Act, the requirements of due care are described. Deliberate termination of life is illegal in most countries in the world.

Recently, two of our conscious ICU patients asked for discontinuation of life-sustaining measures. We want to emphasise the central place for the autonomous choice of the patient and the care of the patient and his or her benefits and interests. 


\section{Patient A}

A ventilator- and inotropes-dependent 61-year-old patient with a history of failed mitral valve replacement and intra-operative total right ventricular myocardial infarction on our ICU requested withdrawal of life-sustaining treatment and if necessary to deliberately terminate her life. In a series of extensive deliberations with the patient and after consulting an independent physician, we agreed to offer her, according to her will, deep palliative sedation followed by withdrawal of life-sustaining treatment. In the presence of her relatives, intravenous administration of midazolam (starting dose $5 \mathrm{mg}$, thereafter $10 \mathrm{mg} / \mathrm{h}$ ) and fentanyl $(100 \mu \mathrm{g}$ starting dose, with $50 \mu \mathrm{g} / \mathrm{h}$ to follow) was started. Within $15 \mathrm{~min}$ she was unconscious. Subsequently, the inotropes, other life-sustaining medication and mechanical ventilation were withdrawn. She died quietly from heart failure and circulatory collapse.

\section{Patient B}

Patient B, a 58-year-old building constructor, was admitted to the general ICU with a traumatic spinal cord injury at the C6-C7 level. In the following weeks, we were unable to wean the patient off the ventilator. Furthermore, he showed no improvements of his spinal cord injury and remained tetraplegic. Several weeks after admission, he repeatedly expressed a clear wish to withdraw treatment and asked the ICU team to take him off the mechanical ventilator. Because of the anticipated anguish, he further wished to be deeply sedated beforehand. After consulting two independent physicians, the nursing staff and a clinical ethicist, the patient was granted his wish. A combination of intravenously administered midazolam (starting with a dose of $5 \mathrm{mg} / \mathrm{h}$, thereafter $10 \mathrm{mg} / \mathrm{h}$ ) and low dose fentanyl $(100 \mu \mathrm{g}$ starting dose, with $50 \mu \mathrm{g} / \mathrm{h}$ to follow) was started, and after he entered a deep sleep, mechanical ventilation was withdrawn. Shortly thereafter, he died peacefully, surrounded by his family.

\section{Discussion}

Approximately $80 \%$ of patients who die in an ICU in The Netherlands die after organ function supportive care or when organ function replacement therapy is withdrawn (unpublished data, Erasmus MC, Department of Intensive Care). Those surviving for a number of hours after discontinuation of treatment can develop symptoms such as dyspnoea-associated respiratory distress, terminal restlessness and 'death rattle'. The majority of terminal patients in the ICU are however unconscious due to the severity of their disease or multiple organ failure, and are not or only superficially aware of the distressing symptoms. The burden of terminal distress in such cases rests predominantly with the relatives [3]. Most symptoms, however, can be successfully prevented or treated [4]. A national guideline in The Netherlands on withdrawal of futile intensive care measures focuses on anticipation of distressing symptoms. Even in The Netherlands, deliberate termination of life of ICU patients is extremely rare [1].

Palliative sedation is initiated in the ICU in the terminal phase of life to prevent or relieve aggravating symptoms such as terminal restlessness, delirium or anxiety. Sedatives are administered aiming to induce a deep unconscious sleep in anticipation of death. In principle, the National Guidelines for Palliative Sedation of the Dutch Royal Society of Medicine (KNMG) [5] are adhered to, based on the understanding that in ICU practice, only midazolam and propofol are used for sedation. Morphine is not an effective sedative and is not used in the ICU as such [6]. In the ICU, the transition from sedation with mechanical ventilation to palliative sedation is usually imperceptible. As a rule, the sedative regime the patient received while being treated with mechanical ventilation will be continued in the palliative phase until death. The dose required in ICU patients can be significantly higher than mentioned in the recommendations in the guidelines. If the patient is adequately sedated before withdrawal of treatment, then this dose is adhered to. It serves no purpose to adjust an adequate sedative dose either to a lower level or to increase it to abide by the guidelines-recommended starting dose. After publication of the guidelines in 2005, palliative sedation was recognised by the Public Prosecutor to be normal medical practice. There is, however, a directive to prosecute and bring before a court anyone who performs an act not stated as such in the professional guidelines and to treat this as a life-terminating act without the consent of the patient. In the ICU, we deviate from the precise statements in the guidelines, but with good reason. During the documented followup of the use of sedatives in patients in the ICU, it is important to judge whether one has acted according to the professional standards. Comparing palliative sedation in the ICU with other non-ICU settings is not realistic.

Crucial in the decision-making process in the described cases is respect for the autonomy of the patient. Based on the law, Dutch caregivers have to respect the wishes of the patient if these are understandable and within the accepted possibilities of medical care and also if the patient is judged to be competent to make these judgments. In the illustrated cases, caregivers had no reasons to doubt the cognitive functioning and competency of the patients.

One cannot always predict with certainty whether or not aggravating symptoms will arise after stopping treatment in the ICU. Patients who are awake may prefer to be unconscious during dying with failing organ functions after withdrawal of therapy. It is our moral duty as caregivers in the ICU to acknowledge this request, and 
applying palliative sedation prior to withdrawing active treatment offers a righteous means [4]. But with this, we digress from the Dutch Guidelines, which state that administering sedatives to patients for the sole reason of the patient's wish to be free of suspected suffering at the end of life, is not permitted. There must be objective proof that there is unbearable suffering, which only can be treated by lowering consciousness of the patient.

Many published ethical analyses on palliative sedation use the doctrine of double effect (DDE), mentioning that palliative sedation may hasten or induce death, and is therefore morally questionable. When evaluating an action, the DDE distinguishes between intended effects and the consequences that are foreseen but unintended. As long as intentions are good, it is permissible to perform actions with foreseen consequences that would be wrong to intend. In this line of thought, deliberately causing death is morally wrong, even if desired by a competent patient whose suffering cannot be relieved in another way. If the patient dies unintentionally as a consequence of another ethically justified intervention (e.g., withdrawal of futile treatment), the action is morally acceptable. The unintended but foreseen effect must also be proportional to the intended good effects. The DDE is often mentioned in justifying the use of opiates and sedatives at the end of life to relieve suffering. There is a growing body of evidence showing that administration of normal doses of sedatives and opiates at the end of life does not shorten life, but prolongs it [7-11], and only scarce anecdotal data mention that opioids can hasten death [12], making the DDE in end-of-life care a myth [13]. It is concluded that "Clinical studies and decades of experience by experts in pain management and palliative care have shown that the double effect of pain medication has little basis in medical fact;...the myth of the double effect of pain medication, directly contributing to the maltreatment of suffering at the end of life. It is ironic that an ethical principle that is used to justify adequate opioid analgesics contributes to the maltreatment of pain" [13]. The same could be said about palliative sedation with barbiturates and benzodiazepines. DDE in end-of-life care is nothing more than a myth, and using it to label palliative sedation and administration of opiates at the end of life questionable and only defendable from the perspective of the DDE, unsound.

When a competent patient on the ICU asks for termination of treatment, we should seriously take this request into deliberation. The principle of respecting autonomy is a strong guidance in bioethics.

The American Academy of Neurology published a position paper concerning the care of conscious, competent patients with profound paralysis [14, 15]. They concluded that such patients have the right to make health care decisions about their own lives, including acceptance or refusal of life-sustaining treatment. Once patients have decided to forego life-sustaining treatment, physicians have an ethical obligation to minimise their subsequent suffering. This is particularly true of profoundly paralysed patients, because cognition and sensation may be intact, and they are capable of great suffering.

\section{Conclusion}

In competent ICU patients in The Netherlands who are terminally dependent on life-sustaining measures, such as mechanical ventilation and administration of vasoactive agents, withdrawal of these measures is ethically good care when they ask for withdrawal. This is not to be seen as deliberate termination of life, even if they die after the withdrawal of life-sustaining measures. Administration of sedatives and analgetics before withdrawal of treatment is normal palliative care. The DDE is not applicable in this situation.

\section{Conflict of interest statement None.}

Open Access This article is distributed under the terms of the Creative Commons Attribution Noncommercial License which permits any noncommercial use, distribution, and reproduction in any medium, provided the original author(s) and source are credited.

\section{References}

1. Kompanje EJ, de Beaufort ID, Bakker J (2007) Euthanasia in intensive care: a 56-year-old man with a pontine hemorrhage resulting in a locked-in syndrome. Crit Care Med 35:2428-2430

2. Kuiper MA, Whetstine LM, Holmes JL, Streat S, Burrows RC, Seppelt I, Crippen D (2007) Euthanasia: a word no longer to be used or abused. Intensive Care Med 33:549-550
3. Kompanje EJ (2006) 'Death rattle' after withdrawal of mechanical ventilation: practical and ethical considerations. Intensive Crit Care Nurs 22:214-219

4. Kompanje EJ, van der Hoven B, Bakker J (2008) Anticipation of distress after discontinuation of mechanical ventilation in the ICU at the end of life. Intensive Care Med 34:1593-1599
5. Verkerk M, van Wijlick E, Legemaate J, de Graeff A (2007) A national guideline for palliative sedation in the Netherlands. J Pain Symptom Manage 34:666-670

6. Bakker J, Jansen TC, Lima A, Kompanje EJ (2008) Why opioids and sedatives may prolong life rather than hasten death after ventilator withdrawal in critically ill patients. Am J Hosp Palliat Care 25:152-154 
7. Edwards MJ (2005) Opioids and benzodiazepines appear paradoxically to delay inevitable death after ventilator withdrawal. J Palliat Care 21:299-302

8. George R, Regnard C (2007) Lethal opioids or dangerous prescribers? Palliat Med 21:77-80

9. Sykes N, Thorns A (2003) Sedative use in the last week of life and the implications for end-of-life decision making. Arch Intern Med 163:341-344

10. Thorns A, Sykes N (2000) Opioid use in last week of life and implications for end-of-life decision-making. Lancet 356:398-399
11. Wilson WC, Smedira NG, Fink C, McDowell JA, Luce JM (1992) Ordering and administration of sedatives and analgesics during the withholding and withdrawal of life support from critically ill patients. JAMA 267:949-953

12. Meier DE, Cassel CK (1983) Euthanasia in old age: a case study and ethical analysis. J Am Geriatr Soc 31:294-298

13. Fohr SA (1998) The double effect of pain medication: separating myth from reality. J Palliat Med 1:315-328
14. (1993) Position statement: certain aspects of the care and management of profoundly and irreversibly paralyzed patients with retained consciousness and cognition. Report of the Ethics and Humanities Subcommittee of the American Academy of Neurology. Neurology 43:222-223

15. Bernat JL, Cranford RE, Kittredge FI Jr, Rosenberg RN (1993) Competent patients with advanced states of permanent paralysis have the right to forgo life-sustaining therapy. Neurology 43:224-225 